\title{
Evaluation of Stabilizing Additives Content in the Mechanical Properties of Elastomeric Compositions Subject to Environmental and Accelerated Aging
}

\author{
Gelsa A. Carpenedo ${ }^{a, b}$, Renan Demori ${ }^{b}$ (D), Larissa N. Carlic (D), Marcelo Giovanela ${ }^{b}$ (D), \\ Marco A. De Paolid ${ }^{*}$ (D), Janaina S. Crespo ${ }^{b *}$ (D) \\ ${ }^{a}$ Vipal Borrachas, Nova Prata, RS, Brasil. \\ ${ }^{b}$ Universidade de Caxias do Sul, Área do Conhecimento de Ciências Exatas e Engenharia, Caxias do \\ Sul, RS, Brasil \\ ${ }^{c}$ Universidade Federal de Santa Catarina, Blumenau, SC, Brasil \\ ${ }^{d}$ Universidade Estadual de Campinas, Instituto de Química, Campinas, SP, Brasil
}

Received: April 02, 2020; Revised: August 31, 2020; Accepted: September 12, 2020

\begin{abstract}
This research aimed to evaluate the ideal proportion of two stabilizers in elastomeric compositions indicated for tire sidewall. The stabilizers applied in different proportions were $N$-1,3-dimethyl-butyl$N$ '-phenyl-p-phenylenediamine (6PPD) and oligomerized 2,2,4-trimethyl-quinoline (TMQ). Nine compositions were prepared with $0.5,1.5$ and $2.5 \mathrm{phr}$ of 6PPD combined with $0.5,1.0$ and $1.5 \mathrm{phr}$ of TMQ. The compounds were exposed to accelerated aging processes, including thermo-oxidative, photochemical and ozone chamber. Also, the samples were aged in the environment for 440 days. At regular intervals, the samples were evaluated. Gas chromatography was used to quantify the content of 6PPD. Overall, the samples exposed to thermo-oxidative aging showed the greatest loss of mechanical properties (tear and tensile strength) as well as the 6PPD content. From the mechanical strength results, it was possible to conclude that the best combination of stabilizers was $2.5 \mathrm{phr}$ of 6PPD and 1.0 of TMQ.
\end{abstract}

Keywords: Elastomers, stabilizers, $6 P P D, T M Q$, tire sidewall.

\section{Introduction}

The tire is composed of components that interact simultaneously and synergistically to ensure its performance during the application and lifecycle. These include the sidewall (the tire side), tread, shoulder, straps and liners ${ }^{1}$; being the belt and sidewall the essential components. During its use, the low bending frequencies of the tire side are related to the balance of the internal pressure that causes tension between the sidewall and the tire belt; and the high frequencies are related to the shear stiffness and longitudinal stiffness ${ }^{2}$. Consequently, it is important to study the aging of the tires' sidewall, because it is in constant dynamic work during use.

Therefore, the tire's performance is assessed by characteristics of the vulcanized compound when exposed to severe conditions of temperature, environment and fatigue. Generally, tests involving tensile strength, compression, and flexural fatigue under accelerated aging conditions provide the information needed about the tire's lifecycle ${ }^{3}$.

In natural (NR) and polybutadiene (BR) rubber researches, the most investigated topic focuses on the oxidative effects, which mainly occur when the unsaturation presented in the polymer main chain is attacked by the oxygen ${ }^{4}$. Additionally, another important effect of aging is caused by ozone. Brand and Gent $^{5}$ defined that the cracks caused by ozone increase linearly with time and its growth rate are proportional to the ozone concentration. In the Counta et al research, the

*E-mail: jscrespo@ucs.br; madpaoli@unicamp.br results showed that tires are subject to many aging factors, including heat, ozone, UV and dynamic stress.

Regarding aging processes and chemical changes in the polymer structure, the onset of degradation is always related to the break of a covalent chemical bond. Depending on how degradation occurs, disruption of bonds can generate reactive species, which in most cases are free radicals. The addition of stabilizing additive like p-phenylenediamines (6PPD) combined with trimethylquinolines (TMQ) as well as microcrystalline waxes offers satisfactory protection to elastomeric artifacts ${ }^{7}$.

During the degradation process, once the chain reaction begins, these radicals quickly combine with oxygen (Figure 1 Step 1) to form peroxyl radicals (Figure 1 - Step 2). This one, in turn, extracts hydrogen from the rubber macromolecule forming a hydroperoxide as well as regenerating the radical to continue the cycle (Figure 1 - Step 3). In addition, the formed hydroperoxide decomposes into two oxygen radicals (Figure 1 - Step 4), which will increase the propagation of the reaction (Figure 1 - Steps 5 and 6).

The scission of the polymeric chain happens, when the energy applied to the molecule is greater than the binding energy. The reduction of the binding energy in the polymeric chain occurs by the presence of branches, tactics, morphology, mechanical stress, presence of contaminants and conditions of the rubber artifact use. The presence of tertiary carbon atoms, for example, implies the existence of $\mathrm{C}-\mathrm{H}$ bonds that can be broken more easily than $\mathrm{C}-\mathrm{H}$ bonds 


\section{Initiation:}

$$
\text { Step } 1 \text { - } \mathrm{PH} \text { (rubber) } \mathrm{O}_{2} \mathrm{P} \bullet+\mathrm{HO}_{2} \mathrm{P}
$$

Propagation:

$$
\begin{aligned}
& \text { Step } 2-\mathrm{P} \bullet+\mathrm{O}_{2} \mathrm{POO} \bullet \\
& \text { Step } 3-\mathrm{POO} \bullet+\mathrm{P}^{\prime} \mathrm{H} \mathrm{POOH}+\mathrm{P}^{\prime} \\
& \text { Step } 4 \text { - } \mathrm{POOH} \mathrm{PO} \bullet+\mathrm{HO} \bullet \\
& \text { Step } 5 \text { - } \mathrm{PO} \bullet+\mathrm{P}^{\prime \prime} \mathrm{H} \mathrm{POH} \bullet+\mathrm{P} \bullet "^{\prime \prime} \\
& \text { Step } 6-\mathrm{OH} \bullet+\mathrm{P}^{\prime \prime \prime} \mathrm{H} \mathrm{H}_{2} \mathrm{O} \bullet+\mathrm{P} \bullet^{\prime \prime \prime}
\end{aligned}
$$

Figure 1. Illustrative scheme of the degradation reaction in an elastomeric matrix ${ }^{7}$.

of primary or secondary carbons. Scission can also occur on double-bonded polymeric chains. The presence of the $\mathrm{C}=\mathrm{C}$ double bond reduces the energy of the adjacent $\mathrm{C}-\mathrm{H}$ bond ${ }^{8}$. The degradation of vulcanized rubber is associated with both breakdowns of the sulfur bonds as well as the scission of the polymeric main chain (either by chemical reaction or mechanical stress). For both processes, there may be a decrease in the mechanical properties of tensile and tear strength.

The ozone attack resistance testing on cured rubber compounds occupies a prominent place in polymer degradation. The compounds' loss of properties during service often results directly in mechanical fatigue fracture initiated by superficial cracking caused by the ozone attack ${ }^{9}$. The interaction with ozone is observed when rubber is tensioned in use, which results in the fail intensification perpendicularly to the applied stress ${ }^{10}$. Only rubbers with unsaturated chains will be degraded by ozone. In the absence of stretching or tensioning, the inner layers of double bonds will not be exposed to ozone. Therefore, the cracks will not grow, remaining only on the superficial layer of the material ${ }^{11,12}$. Usually, the reaction with ozone is electrophilic and starts in places, where the electron density is high ${ }^{13}$.

The term 'stabilizer' is used to describe a wide range of chemical compounds that inhibit degradative processes in polymers. Therefore, there are antioxidants, photostabilizers, metal deactivators and antiacids ${ }^{14}$. The secondary aromatic amines are the most commonly used as primary stabilizers in $\mathrm{C}=\mathrm{C}$ double-bonded polymers, such as synthetic rubbers and NR. These materials are vulcanized in the presence of sulfur compounds and contain carbon black to increase their abrasion resistance. In this context, Dweik and $\mathrm{Scott}^{14}$ proposed a mechanism, where the stabilizer is regenerated in an autocatalytic cycle that involves the intermediate formation of nitroxyl radicals and participation of sulfur compounds.

The compounds used as secondary stabilizers are the trivalent phosphorus compounds such as phosphites or phosphonites; the organic sulfur compounds such as sulfides and metal salts of dialkyldithiocarbamates and dithiophosphates. However, the use of secondary stabilizers in some applications tends to decrease due to their toxicity ${ }^{8}$.
In this research, $N$-1,3-dimethyl-butyl- $N$ '-phenylp-phenylenediamine (6PPD) and oligomerized 2,2,4-trimethylquinoline (TMQ) were used and they are classified as primary stabilizing additives. Additionally, both are of the secondary aromatic amine type. The TQM is an amine (quinoline type) considered to be of high molar mass, low volatility and low cost.

As the stabilizer with a function of antioxidant, it tends to interrupt the sequence of degradation reaction by capturing the free radicals formed and/or by ensuring that the peroxides produced break down into less reactive fragments ${ }^{15,16}$. In turn, the p-phenylenediamines in the 6PPD are stabilizers that have the function of breaking the chain (via donation of a hydrogen atom) forming an aminyl radical ${ }^{17}$.

According to Narathichat ${ }^{18}$, 6PPD has a lower thermal stability than the TMQ. However, TMQ has lower oxidative protection than 6PPD for NR at elevated temperatures. This behavior can be attributed to its lower mobility within the rubber compound due to its high molar mass. Additionally, the energy required to remove the active $\mathrm{H}$ atom in TMQ is greater than in $6 \mathrm{PPD}^{18}$.

In view of all these aspects, this research aims to evaluate the ideal proportion of 6PPD and TMA stabilizers in tire sidewall elastomeric compounds that require long term performance.

\section{Materials and Methods}

\subsection{Materials}

The materials and additives used in the research were provided by Borrachas Vipal S.A(Brazil). The following neat materials were used: zinc oxide ( $\mathrm{ZnO})$ (Votarantim Metais), stearic acid (Sabões Fontana), natural rubber (NR) of the SMR type 5L (Lee Rubber), polybutadiene rubber (BR) (ND 40 - Lanxess), carbon black (NF 330) (Columbian Chemicals of Brazil), stabilizer 6PPD 96\% (Lanxess), stabilizer TMQ (Chemtura), sulfur (Intercuf Indústria e Comércio Ltda), CBS accelerator ( $N$-cyclohexyl-2-benzothiazole sulfenamide) (Lanxess) and TRAE aromatic rubber oil.

\subsection{Compounding}

From a standard sidewall tire compound, various compositions have been developed according to Table 1 .

First, the mixing process occurred in a Banbury internal mixer, Copé brand, with an amount of $1,250 \mathrm{~g}$ per batch, rotor speed of $50 \mathrm{rpm}$ with discharge at a temperature of $150{ }^{\circ} \mathrm{C}$ for $30 \mathrm{~min}$. In the partially homogenized mixture, the acceleration components (sulfur and accelerator additives) were incorporated into an open mixer under the following conditions: temperature of approximately $80^{\circ} \mathrm{C}$ and cylinder friction ratio of $1: 1.25$ for $2 \mathrm{~min}$.

\subsection{Specimen preparation}

The specimens were prepared by compression molding in a Shultz PHS $15 \mathrm{~T}$ hydraulic press operating at $150{ }^{\circ} \mathrm{C}$, pressure of $15 \mathrm{Bar}$ and optimum vulcanization time of $15 \mathrm{~min}$ (determined by oscillatory disc rheometry (MDR). After the $150 \times 150 \times 2 \mathrm{~mm}$ plates were produced, specimens were cut with specific imprints for the tensile strength and tear strength mechanical tests. 
Table 1. Compositions studied in this research.

\begin{tabular}{|c|c|c|c|c|c|c|c|c|c|c|}
\hline \multirow{2}{*}{ Compounds (phr) } & \multicolumn{10}{|c|}{ Compositions } \\
\hline & 0 & 1 & 2 & 3 & 4 & 5 & 6 & 7 & 8 & 9 \\
\hline NR & 50 & 50 & 50 & 50 & 50 & 50 & 50 & 50 & 50 & 50 \\
\hline $\mathrm{BR}$ & 50 & 50 & 50 & 50 & 50 & 50 & 50 & 50 & 50 & 50 \\
\hline NF 330 & 50 & 50 & 50 & 50 & 50 & 50 & 50 & 50 & 50 & 50 \\
\hline Oil & 10 & 10 & 10 & 10 & 10 & 10 & 10 & 10 & 10 & 10 \\
\hline Stearic acid & 2 & 2 & 2 & 2 & 2 & 2 & 2 & 2 & 2 & 2 \\
\hline $\mathrm{ZnO}$ & 3 & 3 & 3 & 3 & 3 & 3 & 3 & 3 & 3 & 3 \\
\hline Sulfur & 1.75 & 1.75 & 1.75 & 1.75 & 1.75 & 1.75 & 1.75 & 1.75 & 1.75 & 1.75 \\
\hline CBS & 1 & 1 & 1 & 1 & 1 & 1 & 1 & 1 & 1 & 1 \\
\hline TMQ & - & 0.5 & 0.5 & 0.5 & 1 & 1 & 1 & 1.5 & 1.5 & 1.5 \\
\hline $6 \mathrm{PPD}$ & - & 0.5 & 1.5 & 2.5 & 0.5 & 1.5 & 2.5 & 0.5 & 1.5 & 2.5 \\
\hline
\end{tabular}

\subsection{Mechanical tests}

The tear strength test was performed according to ASTM D 624-12 specimen Type $\mathrm{C}^{19}$. The tests were conducted on a Tensometer 2000 (T2000) universal testing machine, Alpha Technologies, using a load cell and speed of $5 \mathrm{kN}$ and $500 \mathrm{~mm} \mathrm{~min}^{-1}$, respectively.

In turn, the tensile strength test was performed according to ASTM D 412-06 specimen Type $\mathrm{C}^{20}$. A $5 \mathrm{kN}$ load cell and speed of $500 \mathrm{~mm} \mathrm{~min}-1$ were used in a Tensometer 2000 (T2000) Alpha Technologies universal testing machine.

\subsection{Gas chromatography $(G C)$}

From the aged and non-aged specimens, $1.0 \mathrm{~g}$ of the material was ground and immersed in acetone for $16 \mathrm{~h}$ at room temperature for the 6PPD extraction. Subsequently, the acetone solution was injected into the Clarus 600 Perkin Elmer gas chromatograph, according to ASTM D 3156-9621. The conditions of the analysis were: initial temperature of $20^{\circ} \mathrm{C}$, heating rate of $20^{\circ} \mathrm{C} \mathrm{min}{ }^{-1}$, final temperature of $300{ }^{\circ} \mathrm{C}$ during $29 \mathrm{~min}$, flame ionization detector and detector temperature of $330{ }^{\circ} \mathrm{C}$, glass column $(100 \%$ polysiloxane $)$ with a length of $30 \mathrm{~m}$, diameter of $25 \mathrm{~mm}$ and a $0.30 \mu \mathrm{m}$ film thickness. The injection volume was $1.0 \mu \mathrm{L}$ and the flow $1.0 \mathrm{~mL} \mathrm{~min}{ }^{-1}$. The carrier gas used was helium.

Fragments of $1.0 \mathrm{~g}$ of the $1.5 \mathrm{phr}$ TMQ and $2.5 \mathrm{phr} 6 \mathrm{PPD}$ samples were aged for $72 \mathrm{~h}$ in an oven at $70{ }^{\circ} \mathrm{C}$ within a sealed vial. The gas formed in the vial was extracted with a $10 \mathrm{~mL}$ syringe and diluted with $1.5 \mathrm{~mL}$ of acetone. Subsequently, acetone was analyzed by gas chromatography with a flame ionization detector. The detector temperature was $330^{\circ} \mathrm{C}$.

\subsection{Thermo-oxidative aging}

The samples were submitted to accelerated thermo-oxidative aging (thermolysis) conducted in an oven (Marconi, model MA 035), with forced air circulation and absence of light for 24 , 48 and $72 \mathrm{~h}$ at $70{ }^{\circ} \mathrm{C}$, according to ASTM D 572-0422. After aging, the samples were tested by tensile and tear strength and 6PPD content. From the results, the property retention for each aging time was determined according to Equation 1:

$\%$ retention $=\left(\frac{P_{\text {final }}}{P_{\text {initial }}}\right) 100$

where,

$\mathrm{P}_{\text {final }}$ is the value of the properties measured after aging; and
$\mathrm{P}_{\text {initial }}$ is the properties measured before aging test.

\subsection{Photochemical aging}

The photochemical accelerated aging (photolysis) was conducted in a UV chamber according to ASTM G 154$06^{23}$ operating at $50{ }^{\circ} \mathrm{C}$ for 120,240 and $480 \mathrm{~h}$ into two cycles of $4 \mathrm{~h}: 50 \%$ of the time subjected to condensation and $50 \%$ subjected to UVB radiation. The retention of the tensile and tear strength properties, as well as the 6PPD content, was calculated according to Equation 1.

\subsection{Ozone chamber aging}

Ozone chamber accelerated aging test was conducted at $40{ }^{\circ} \mathrm{C}$ and 50 pphm of ozone concentration during 90 , 180 and $360 \mathrm{~h}$, based on the ASTM D 1149-200724. Property retention calculations were performed according to Equation 1.

\subsection{Environmental aging}

The environmental aging test was performed at the Borrachas Vipal Rubber company for a period of 440 days, from November of 2011 until February 2013, based on ISO $877-2^{25}$. Table 2 shows the weather condition such as average rainfall, minimum and maximum temperature, and relative humidity which were obtained from the Embrapa Uva e Vinho, Meteorological Station, Brazil (coordinates 2909'52.4”'S 51³2'02.8' W) ${ }^{26}$.

The specimens were arranged on the exposed metallic structure at 3 meters from the ground located in an open area without being exceeded by other objects. The specimens were collected and evaluated after periods of 20,40, 80, $120,160,320$ and 440 days of exposure. The specimens were gently cleaned using a towel and left in air for $24 \mathrm{~h}$ at room temperature before proceeding to the required test. The retention of properties was calculated according to Equation 1.

\subsection{Dynamic-mechanical thermal analysis (DMTA)}

A vulcanized compound was subjected to the DMTA test at a frequency of $10 \mathrm{~Hz}$, strain $0.06 \%$ in the temperature ranging from $-125{ }^{\circ} \mathrm{C}$ to $0{ }^{\circ} \mathrm{C}$ and heating rate of $2{ }^{\circ} \mathrm{C} \mathrm{min}^{-1}$. The test was performed using a TA Instruments DMA Q800 testing machine operating in a single cantilever for $1.89 \times 6.07 \times 13.72 \mathrm{~mm}$ specimen. 
Table 2. Weather parameters throughout the environmental test (November of 2011 until February 2013).

\begin{tabular}{|c|c|c|c|c|c|c|c|}
\hline Year & Solar radiation & $\begin{array}{l}\text { Relative } \\
\text { humidity }\end{array}$ & $\begin{array}{c}\text { Winter } \\
\text { temperature }\end{array}$ & $\begin{array}{c}\text { Summer } \\
\text { temperature }\end{array}$ & Precipitation & Sunstroke & $\begin{array}{c}\text { Average Wind } \\
\text { speed }\end{array}$ \\
\hline & $\left(\mathrm{kJ} / \mathrm{m}^{2}\right)$ & $(\%)$ & $\left(\min\right.$ to $\left.\max { }^{\circ} \mathrm{C}\right)$ & $\left(\right.$ min to $\left.\max { }^{\circ} \mathrm{C}\right)$ & $(\mathrm{mm})$ & $\left(\mathrm{W} / \mathrm{m}^{2}\right)$ & $(\mathrm{m} / \mathrm{s})$ \\
\hline 2011-2012 & 826.0 & 73 & 7.3 to 22.8 & 15.5 to 29.3 & 116.7 & 215.6 & 2.5 \\
\hline 2013 & 839.7 & 75 & 7.3 a 19.6 & 14.6 to 28.2 & 163.8 & 204.7 & 2.2 \\
\hline
\end{tabular}

\section{Results and Discussion}

\subsection{Definition of 6PPD and TMQ content in the compositions}

The results of the 6PPD retention are based on the compositions showed in Table 1. Since 6PPD is consumed during the vulcanization process, Figure 2 shows the difference of 6PPD before versus right after the vulcanized composition. The amount of 6PPD retained after the vulcanization process are: compositions 1,4 and $7(\sim 81.5 \%)$; compositions 2,5 and $8(\sim 71.2 \%)$; compositions 3,6 and $9(\sim 71.4 \%)$. This value was used to determine the retention content in this study.

The first part of this study was the definition of the 6PPD and TMQ ratio in the rubber compound. Hence, it was evaluated nine compositions (Table 1) to define the stabilizers' ratio in the rubber compounding aging resistance. Following, specimens for tear and tensile strength were prepared and submitted to aging tests and further evaluation by tensile properties.

As a result of the tensile tests, the retention of the tear strength indicated that in environmental aging the properties maintenance is independent of the protective content used. However, for the aging in the ozone chamber, the properties were maintained with $1.5 \mathrm{phr}$ of 6PPD and $0.5 \mathrm{phr}$ of TMQ (composition 2).

Additionally, for the photochemical aging in a UV chamber, the properties maintenance occurred with $1.5 \mathrm{phr}$ of 6PPD and $1.5 \mathrm{phr}$ of TMQ (composition 8), while for the thermo-oxidative aging in the oven, this occurred with $2.5 \mathrm{phr}$ of 6PPD and $1.0 \mathrm{phr}$ of TMQ (composition 6). In turn, for the environmental aging, stress at break was maintained regardless of the protective content. For the aging in the ozone chamber, property maintenance occurred with $0.5 \mathrm{phr}$ of 6PPD and $0.5 \mathrm{phr}$ of TMQ (composition 1).

Regarding the results of the photochemical aging in the UV chamber, it was observed that the properties maintenance occurred with $2.5 \mathrm{phr}$ of 6PPD and $0.5 \mathrm{phr}$ TMQ (composition 3 ), and for thermo-oxidative aging in an oven, properties maintenance occurred with $2.5 \mathrm{phr}$ of 6PPD and $1.0 \mathrm{phr}$ of TMQ (composition 6).

On the other hand, for the retention of the elongation at break, we observed that in environmental and ozone chamber aging the properties maintenance was independent of the protective ratio content. For photochemical aging, the properties were maintained with the lowest protective content, while for the thermo-oxidative aging in the oven, the property maintenance occurred with $2.5 \mathrm{phr}$ of 6PPD and 1.0 phr of TMQ (composition 6).

For environmental aging in ozone chamber and photochemical in UV chamber, the best retention occurred with $0.5 \mathrm{phr}$ of TMQ and 2.5 phr of 6PPD (composition 3), while for thermo-

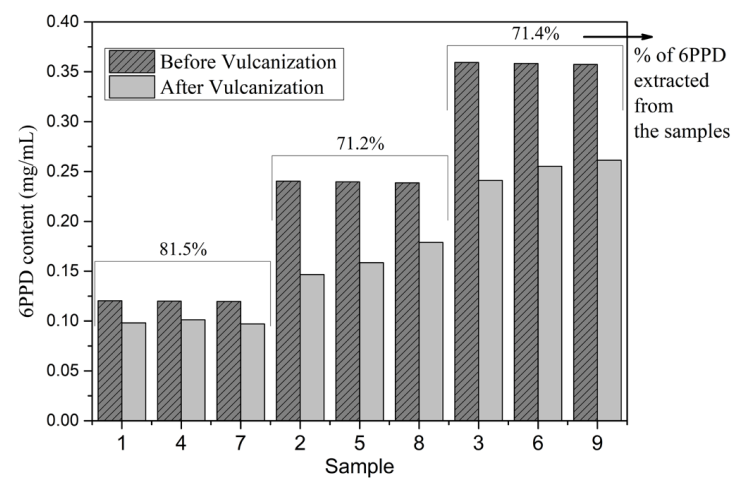

Figure 2. 6PPD content measured after vulcanization process.

oxidative aging in an oven the best retention occurred at $1.5 \mathrm{phr}$ of TMQ and $0.5 \mathrm{phr}$ of 6PPD (composition 7).

From the analyzes performed with the various concentrations of 6PPD and TMQ, the best performance occurred with $2.5 \mathrm{phr}$ of 6PPD and $1.0 \mathrm{phr}$ of TMQ (composition 6) in the thermo-oxidative aging in an oven, which was considered the most aggressive in terms of property loss of tear strength, tensile strength and the consumption of 6PPD content. In this scenario, the formulation 6 was chosen to the second part of this study, where further evaluations were performed. Thus, new specimens were prepared and subjected to aging tests.

Figures 3 to 11 show the results indicating the best stabilizing additive content in thermo-oxidative aging after $72 \mathrm{~h}$. Figure 3 shows tear strength in thermo-oxidative aging in an oven using $0.5 \mathrm{phr}$ of TMQ in combination with different 6PPD contents. As can be seen, the best result obtained was using $1.5 \mathrm{phr}$ of 6PPD, reaching $68 \%$ of the retention for this property.

In turn, Figure 4 shows the stress at break for thermooxidative aging in an oven using 0.5 phr of TMQ in combination with different contents of 6PPD. Here, the best property retention was found with $1.5 \mathrm{phr}$ of $6 \mathrm{PPD}$, reaching $68 \%$.

In the retention of thermo-oxidative aging in the oven using $0.5 \mathrm{phr}$ of TMQ, in combination with different 6PPD contents (Figure 5), we observed that the best retention of properties was found at $1.5 \mathrm{phr}$, which reached approximately $22 \%$.

Figure 6 shows the retention of tear strength in oven thermo-oxidative aging using 1.0 phr of TMQ in combination with different 6PPD contents. We observed that the superior retention of properties was found with $2.5 \mathrm{phr}$ of 6PPD, which reached approximately $80 \%$.

In Figure 7, we show the retention of tear strength for oven thermo-oxidative aging using $1.0 \mathrm{phr}$ of TMQ in combination with different 6PPD contents. We observed 


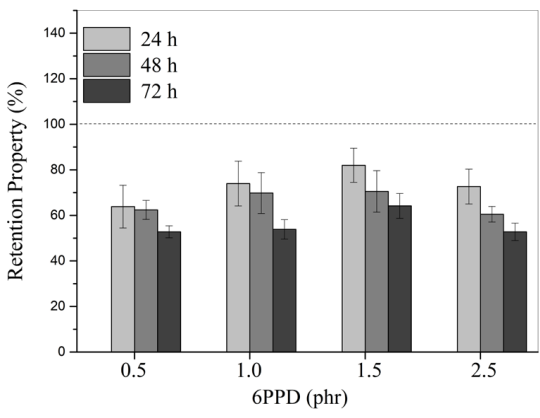

Figure 3. Retention of tear strength in oven thermo-oxidative aging comprising $0.5 \mathrm{phr}$ of TMQ in combination with different 6PPD contents.

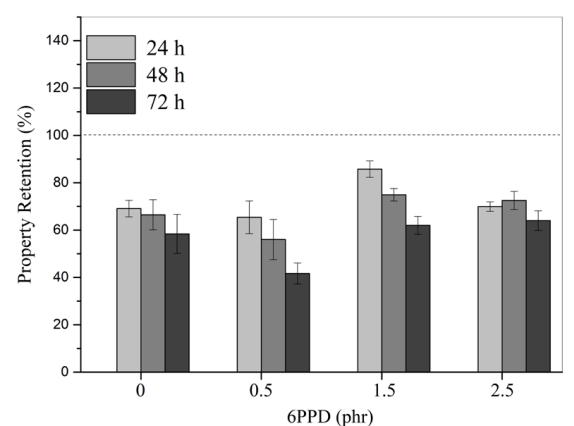

Figure 4. Retention of tensile strength at thermal-oxidative aging in oven comprising $0.5 \mathrm{phr}$ of TMQ in combination with different 6PPD contents.

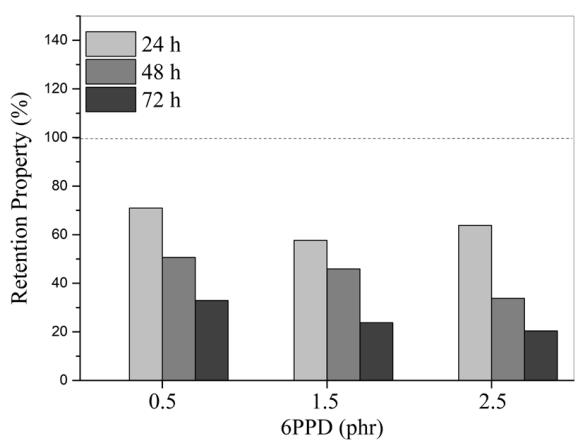

Figure 5. Retention of $6 \mathrm{PPD}$ in oven thermo-oxidative aging comprising $0.5 \mathrm{phr}$ of TMQ in combination with different $6 \mathrm{PPD}$ contents.

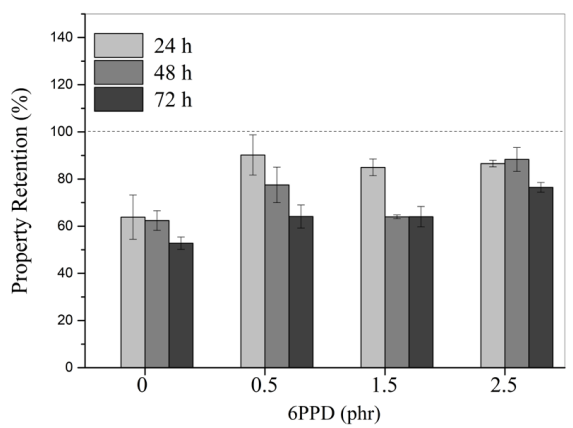

Figure 6. Retention of tear resistance in oven thermo-oxidative aging comprising $1.0 \mathrm{phr}$ of TMQ in combination with different 6PPD contents.

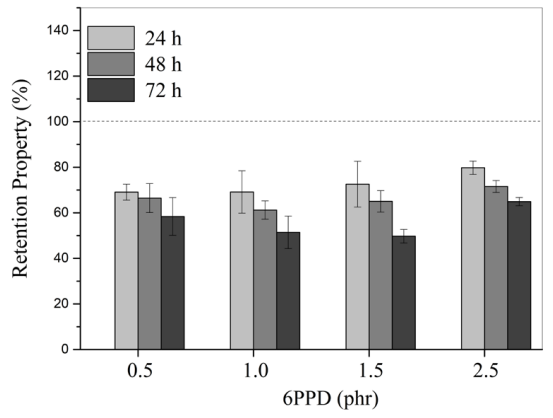

Figure 7. Retention of tear strength for oven thermal-oxidative aging comprising $1.0 \mathrm{phr}$ of TMQ in combination with different 6PPD contents.

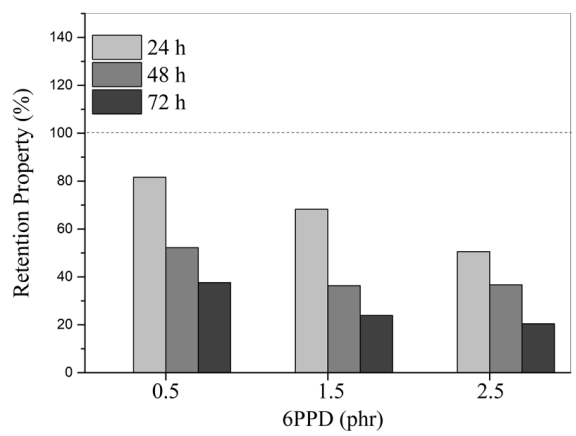

Figure 8. Retention of 6PPD in oven thermo-oxidative aging comprising $1.5 \mathrm{phr}$ of TMQ in combination with different 6PPD contents.

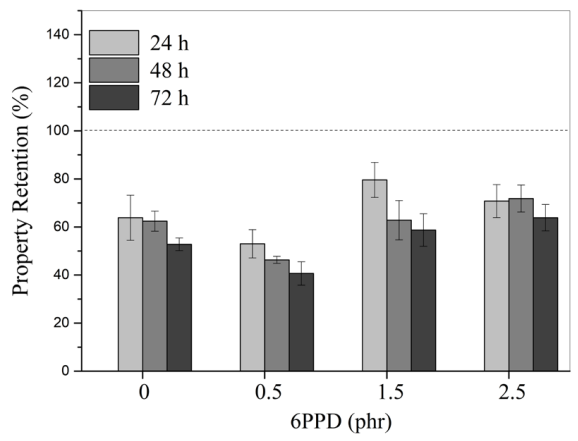

Figure 9. Retention of tear strength for oven thermal-oxidative aging comprising $1.5 \mathrm{phr}$ of TMQ in combination with different 6PPD contents.

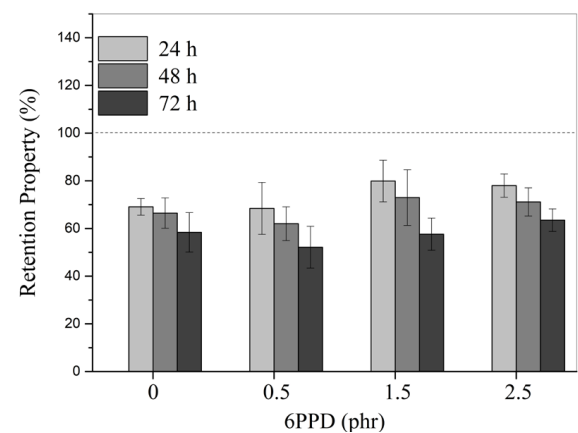

Figure 10. Retention of tensile strength in oven thermal-oxidative aging comprising $1.5 \mathrm{phr}$ of TMQ in combination with different 6PPD contents. 


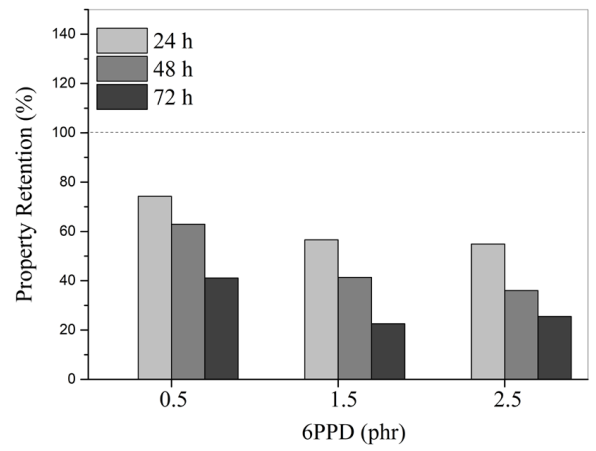

Figure 11. Retention of 6PPD in oven thermo-oxidative aging comprising $1.5 \mathrm{phr}$ of TMQ in combination with different 6PPD contents.

that the best property retention was found with $2.5 \mathrm{phr}$ of $6 \mathrm{PPD}$, reaching $70 \%$.

On the other hand, Figure 8 shows the retention of 6PPD in oven thermo-oxidative aging using $1.0 \mathrm{phr}$ of TMQ in combination with different 6PPD contents. We observed that the best retention of the property occurred with $0.5 \mathrm{phr}$, which reached approximately $40 \%$.

Tear strength retention for oven thermal-oxidative aging using $1.5 \mathrm{phr}$ of TMQ in combination with different 6PPD contents is shown in Figure 9. We observed that the best retention of the property was found at $2.5 \mathrm{phr} 6 \mathrm{PPD}$, which reached $78 \%$.

Figure 10 shows the stress at break retention for oven thermo-oxidative aging using $1.5 \mathrm{phr}$ of TMQ in combination with different 6PPD contents. We observed the best retention of the property with $2.5 \mathrm{phr}$ of $6 \mathrm{PPD}$, reaching $70 \%$.

In Figure 11, we show the retention of the 6PPD in oven thermo-oxidative aging using $1.5 \mathrm{phr}$ of TMQ in combination with different 6PPD contents. We observed that the best retention of the property was found at $0.5 \mathrm{phr}$, which reached $40 \%$. In the results related to Figures 4 to 11 , we observed that the highest consumption of 6PPD was for the composition with $1.5 \mathrm{phr}$ of TMQ.

By evaluating the results, the combination of the stabilizing additives presented in Figure 6 (1.0 phr of TMQ) was selected to continue this study, since retention property of the tear resistance is important for the tire sidewall.

\subsection{Environmental aging}

The environmental aging testing took place in the periods of 20,40, 80, 120,160, 320 and 440 days. After each period, the samples were subjected to mechanical testing and quantification of 6PPD content (Figure 12).

It can be observed that up to 440 days the mechanical properties showed that the reduction of tear and tensile strength, as well as elongation at break, was less than $10 \%$. Additionally, there was a gradual reduction in 6PPD content by approximately $56 \%$ after 440 days of exposure time.

Apparently, the consumption of the stabilizing additive is not directly related to the loss of tear and tensile strength as well as the elongation at break. This observation is possibly, indicating that the elastomeric matrix has not yet started the degradation process.

The specimens aged at the environment were exposed to the ozone, $U V$ radiation and oxygen combined with variations

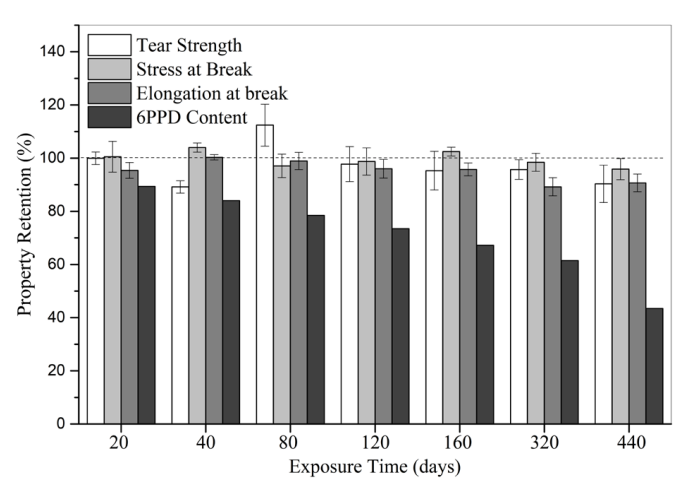

Figure 12. Retention of property in environmental aging of the composition comprising $2.5 \mathrm{phr}$ of 6PPD and $1.0 \mathrm{phr}$ of TMQ.

of weather conditions of temperature and humidity. Therefore, after 440 days the specimens experienced chain scission of the cross-linking on the surface and also within the material.

Thus, the consumption of 6PPD was significant, since the test started in November of 2011 until February 2013 , with temperature variation from $7.3^{\circ} \mathrm{C}$ to $29.3^{\circ} \mathrm{C}$, comprising two summer seasons with temperature variations between $17^{\circ} \mathrm{C}$ and $29.3{ }^{\circ} \mathrm{C}^{27}$. In such a climate, the surface temperature of rubber specimens reaches as high as $50^{\circ} \mathrm{C}$ under direct sunlight ${ }^{28}$. Since temperature increases, the heat may contribute to the stabilizing additive to migrate to the surface and subsequently reacting with the oxygen in the outer region of the elastomer ${ }^{29}$, being consumed. On the other hand, it must also be considered that the increase in temperature increases the solubility of the additive in the matrix, which leads to a reduction in its consumption. In this study, the results indicate that consumption appears to be associated with the migration of the additive to the surface.

However, 6PPD content that remained in the samples in combination with the TMQ was sufficient to maintain the properties of the elastomeric matrix. The combination of the additives might be the reason for better withstanding property in natural weathering ${ }^{30}$. The antioxidant can deactivate the absorbed light, thereby reducing radical formation, which also resulted in the reduction of photooxidation ${ }^{28,30}$.

\subsection{Aging in an ozone chamber}

The aging in the ozone chamber was performed for periods of 80, 160 and $320 \mathrm{~h}$ (Figure 13) without any strain. There was approximately $18 \%$ drop in tear strength after $80 \mathrm{~h}$ of exposure test and thereafter the mechanical properties remained constant.

It was also observed that the elongation at break did not change and stress at break decreased by $12 \%$ after $320 \mathrm{~h}$ of exposure test. There was a gradual consumption of $6 \mathrm{PPD}$, reaching up to $10 \%$. This accelerated aging was less aggressive because just caused little variations in the mechanical properties of the compositions. It occurred because only tensioned elastomers are attacked by ozone, resulting in deep cracks perpendicularly to the applied tension ${ }^{5}$. Probably, during the aging test, the composition's tear strength was more affected by the elastomeric chain scission than the changes in crosslinking density ${ }^{31}$. 


\subsection{Photochemical aging in UV chamber}

The accelerated aging test in the UV chamber occurred at 120,240 and $480 \mathrm{~h}$. The results showed that the stabilizing additives had a protective effect in the compositions (Figure 14).

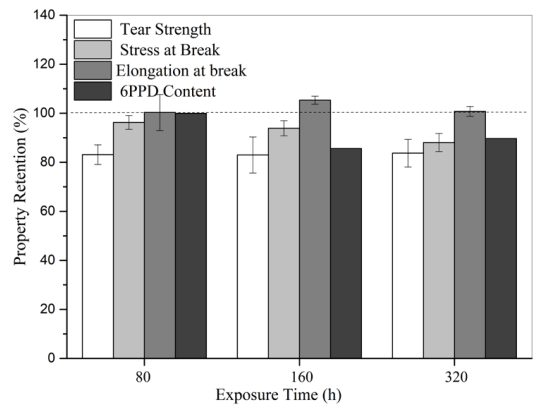

Figure 13. Retention of mechanical properties aged in the ozone chamber of the compositions comprising $2.5 \mathrm{phr}$ of $6 \mathrm{PPD}$ and 1.0 phr of TMQ.

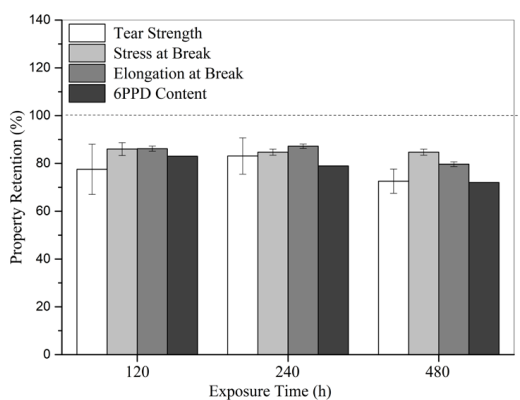

Figure 14. Retention of mechanical property in UV chamber photochemical aging of the compositions comprising $2.5 \mathrm{phr}$ of 6PPD and $1.0 \mathrm{phr}$ of TMQ.

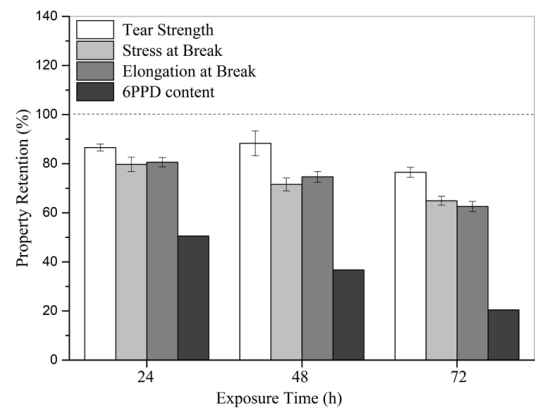

Figure 15. Retention of properties in oven thermo-oxidative aging of the composition comprising $2.5 \mathrm{phr}$ of $6 \mathrm{PPD}$ and $1.0 \mathrm{phr}$ of TMQ.

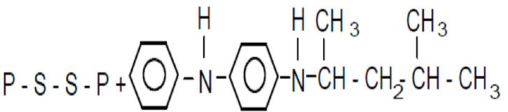

$$
\begin{aligned}
& 10^{0}
\end{aligned}
$$

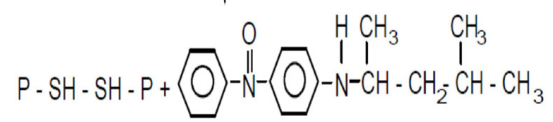

Figure 16. Redox mechanism between stabilizer and elastomer ${ }^{30}$.
The results for $120 \mathrm{~h}$ of testing showed a decrease of up to $20 \%$ in the tear strength and around $15 \%$ in the elongation at break. The properties maintenance occurred over time considering the standard deviation. The consumption of $6 \mathrm{PPD}$ content was gradually reaching up to $25 \%$ and it seems to be associated with the decreased in mechanical properties. For these specimens, probably the cross-linking formation, as well as chain scission, occurred in the highest proportion than in the ozone chamber. According to Douminge et al. ${ }^{32}$, the competition among sulfur bonds and chain scission during degradation lead to physical modifications of the macromolecular chains. These modifications may be associated with a decrease of mechanical properties (as tear resistance, stress and elongation at break) when exposed to photochemical aging.

\subsection{Thermo-oxidative aging in oven}

The retention of properties after the forced-air oven heat-oxidative aging test decreased gradually at 24,48 and $72 \mathrm{~h}$ (Figure 15).

The mechanical properties, stress and elongation at break decreased up to $37 \%$ for $72 \mathrm{~h}$ of exposure. In turn, tear strength decreased by up to $22 \%$ with $72 \mathrm{~h}$ of exposure. The consumption of 6PPD was gradual, reaching $80 \%$ and is related to the reduction of mechanical properties. The aging mechanism in this scenario is caused by temperature ${ }^{32}$. The stress and elongation at break of aged specimens were reduced by thermal aging ${ }^{33}$ and the phenomenon can be attributed to the scission of poly and disulfide bonds and the formation of additional monosulfide bonds. The scission of poly and disulfide bonds is caused by the stabilizer hydrogen atoms in a condition, where the vulcanized elastomer and the stabilizer form a redox system, as shown in Figure $16^{33}$.

\subsection{Dynamic mechanical thermal analysis (DMTA)}

The aged specimens were submitted to DMTA test to evaluate if aging influences the glass transition of the rubber compositions. The loss factor $(\tan \delta)$ is the quotient between loss modulus (viscous component) and the storage modulus (elastic component) response of the polymeric material $\left(E^{\prime \prime} / E^{\prime}\right)^{33,34}$. As shown in Figure 17, in the range of $-60^{\circ} \mathrm{C}$ and $-40{ }^{\circ} \mathrm{C}$ there is a transition region, characterized by the maximum peak of the $\tan \delta$ curve. Additionally, it defines the glass transition temperature ( $T g$ ) of the compositions studied.

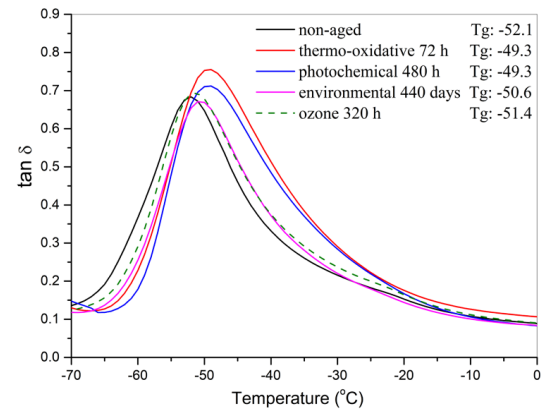

Figure 17. Aging effect on $\tan \delta$ behavior as a function of temperature in compositions comprising $2.5 \mathrm{phr}$ of $6 \mathrm{PPD}$ and $1.0 \mathrm{phr}$ of TMQ (standard deviation in the temperature determination is $\pm 0.5^{\circ} \mathrm{C}$ ). 
From the results, it was found that the oven thermo-oxidative aging resulted in the displacement of $T g$ values to higher temperatures compared to the non-aged sample. This change is associated with the reduction of the polymeric chain's mobility as a result of the increased crosslinking density after aging ${ }^{35}$.

\section{Conclusions}

From this research, it was possible to indicate that the stabilizing additives used in the compositions helped to maintain the integrity of the mechanical properties after aging tests. The most suitable concentration of stabilizing additives to maintain the mechanical properties of the studied compositions was $2.5 \mathrm{phr}$ of 6PPD and $1.0 \mathrm{phr}$ of TMQ. The use of higher TMQ contents did not contribute to improving mechanical properties.

From all the aging tests performed in this research, the most significant change related to the compositions' molecular structure and consequently the loss of properties and consumption of 6PPD occurred in the oven thermooxidative aging.

During the aging test, temperature showed to be the determining factor that contributed to accelerating the degradation and significant reduction of the 6PPD content, which occurs basically by the chemical reaction with oxygen. Therefore, it is the most suitable aging in order to evaluate the effects promoted by the stabilizing additives.

\section{Acknowledgments}

The authors thank Universidade de Caxias do Sul, Borrachas Vipal, Coordenação de Aperfeiçoamento de Pessoal de Nível Superior (CAPES) and Conselho Nacional de Desenvolvimento Científico e Tecnológico (CNPq).

\section{References}

1. Tonkovich A, Li Z, DiCecco S, Altenhof W, Banting R, $\mathrm{Hu}$ H. Experimental observations of tire deformation characteristics on heavy mining vehicles under static and quasi-static loading. J Terramechs. 2012;49:215-31.

2. Pinnington R. A wave model of a circular tire. Part 2: Side-wall and force transmission modeling. J Sound Vibrat. 2006;290:133-68.

3. Parra DF, Freire MTA, De Paoli MA. Diffusion of amine stabilizers in vulcanized natural rubber compositions used in tires. J Appl Polym Sci. 1999;75:670-76.

4. Amram B, Bokobza L, Queslel JP, Monnerie L. Fouriertransform infra-red dichroism study of molecular orientation in synthetic high cis-1,4-polyisoprene in natural rubber. Polymer (Guildf). 1986;27:877-82.

5. Braden M. The attack of ozone on stretched rubber. J Appl Polym Sci. 1960;3:90-9.

6. LaCounta BJ, Castroa JM, Ignatz-Hoover F. Development of a service-simulating, accelerated aging test method for exterior tire rubber compounds. Polym. Degrad. Stab. 2002;75:213-27.

7. Yehia A, Khalifa D, Ghanem N. Compounding and testing of weather-resistant rubber - I. Eur Polym J. 1971;7:549-57.

8. De Paoli MA. Degradação e estabilização de polímeros. São Paulo: Editora Artliber; 2008.

9. Veiyh AG, Evans RL. Effect of atmospheric pressure on ozone cracking of rubber. Polym Test. 1980;1:27-38.
10. Radhakrishnan K, Alex R, Unnikrishnan G. Thermal, ozone and gamma ageing of styrene butadiene rubber and poly(ethylene-co-vinyl acetate) blends. Polym Degrad Stabil. 2006;91:902-10.

11. Budrugeac P. Accelerated thermal ageing of nitrile-butadiene rubber under air pressure. Polym Degrad Stabil. 1995;47:12932.

12. Ohm R. Introduction to rubber compounding. 13rd ed. Norwalk: Vanderbilt Company; 1990.

13. Saito Y. Introduction to polymers, science technology. Bookboon; 1995

14. Dweik HS, Scott G. Mechanisms of antioxidant action: aromatic Nitroxyl radicals and their derived hydroxylamines as antifatigue agents for natural rubber. Rubber Chem Technol. 1984;57:743.

15. Schwarzenbach K. Plastics additives handbook. Munich: Hanz Zweifel publishing; 2001.

16. Niyogi UK. Polymer Additives and Compounding. Polym. Sci. 2007;19:1-29.

17. Narathichat M, Sahakaro K, Nakason C. Assessment degradation of natural rubber by moving die processability test and ftir spectroscopy. J Appl Polym Sci. 2009;115:17029.

18. Gugumus F. Oxidation inhibition in organic materials. Boca Raton: CRC Press; 1990.

19. ASTM International. ASTM D624: Standard test method for tear strength of conventional vulcanized rubber and thermoplastic elastomers: 2012. West Conshohocken, PA: ASTM; 2012.

20. ASTM International. ASTM D412: Standard test methods for vulcanized rubber and thermoplastic elastomers - tension: 2006. West Conshohocken, PA: ASTM; 2006.

21. ASTM International. ASTM D3156: Standard Practice for Rubber - Chromatographic Analysis of Antidegradants (Antioxidants, Antiozonants and Stabilizers): 1996. West Conshohocken, PA: ASTM; 1996.

22. ASTM International. ASTM D572: Standard Test Method for Rubber - Deterioration by Heat and Oxygen: 2010. West Conshohocken, PA: ASTM; 2010.

23. ASTM International. ASTM G154: Standard Practice for Operating Fluorescent Light Apparatus for UV Exposure of nonmetallic Materials: 2006. West Conshohocken, PA: ASTM; 2006.

24. ASTM International. ASTM D1149: Standard Test Method for Rubber Deterioration - Surface Ozone Cracking in a Chamber: 2007. West Conshohocken, PA: ASTM; 2007.

25. International Organization for Standardization. ISO 8772:2009. Standard Test Methods of exposure to solar radiation. Part 2: Direct weathering and exposure behind window glass. Genebra, Suíça: ISO; 2009.

26. EMBRAPA [Internet]. Meteorological Station, Brazil. Bento Gonçalves: Embrapa Uva e Vinho. [cited 2020 July 15] Available from https://www.embrapa.br/uva-e-vinho/ dados-meteorologicos/bento-goncalves.

27. Ratrout N, Mahmoud I. Adequacy of the tensile/elongation test as a quality control criterion for vehicle tires. Polym Test. 2006;25:588-96.

28. Huang D, LaCount BJ, Castro JM, Ignatz-Hoover F. Development of a service-simulating, accelerated aging test method for exterior tire rubber compounds I. Cyclic aging. Polym Degrad Stabil. 2001;74(2):353-62.

29. Varghese S, Kuriakose B, Thomas S. Short sisal fiber reinforced natural rubber composites: high-energy radiation, thermal and ozone degradation. Polym Degrad Stabil. 1994;44:55-61. 
30. Zulkepli NN, Ismail H. A Study of FTIR, thermal properties and natural weathering test on NBR virgin/recycled with SBR blends. Polym Plast Technol Eng. 2012;51(4):350-7.

31. Martin M, De SK. Thermo-oxidative ageing and its effect on the network structure and fracture mode of natural rubber vulcanizates. Polymer (Guildf). 1983;24:1042-54.

32. Douminge L, Bernard J, Mallarino S. Extrinsic fluorescence as a sensitive method for studying photo-degradation of high density polyethylene correlated with mechanical stresses. Curr Appl Phys. 2013;13:1751-7.
33. Huang D, Castro J, Ignatz-Hoover F. Development of a servicesimulating, accelerated aging test method for exterior tire rubber compounds I, Cyclic aging. Polym Degrad Stabil. 2001;74:353-62.

34. Menard K. Dynamic mechanical analysis: a practical introduction. Boca Raton: CRC; 2008.

35. Carli LN, Bianchi O, Mauler RS, Crespo JS. Accelerated Aging of elastomeric composites with vulcanized ground scraps. J Appl Polym Sci. 2010;123:280-5. 